\title{
К ПРОБЛЕМЕ СЕМАНТИКИ ФРАЗЕОЛОГИЧЕСКИХ ЕДИНИЦ
}

\section{ON THE PROBLEM OF SEMANTICS OF PHRASEOLOGICAL UNITS}

Hu. Aliyeva

Summary: The article is devoted to the study of the semantic properties of the components of phraseological units (PU) of the modern language. When considering the semantic characteristics of phraseological units, we proceed from the functions of the ratio of their form and content. The purpose of the research is to study the semantic properties of phraseological units components and elements of phraseological meaning, to identify on this basis their pragmatic essence, cognitive and linguistic features. The tasks of the research included: to analyze and describe the conditions of the semantic characteristics of phraseological components, to determine the informative capacity of phraseological units, presented in their content structure.

Keywords: phraseological unit, semantics, component, stability, word metaphorization, word in free combination.

\author{
Алиева Усния Новруз гызы \\ доктор философии по филологии, старший \\ nреподаватель, Бакинский славянский университет \\ al_hus@list.ru
}

Аннотация: Статья посвящена исследованию семантических свойств компонентов фразеологических единиц (ФЕ) в современном русском языке. При рассмотрении семантической характеристики ФЕ мы исходим из особенностей соотношения их формы и содержания. Целью является изучение семантических свойств компонентов ФЕ и элементов фразеологического значения, выявление на этой основе их прагматической сущности, когнитивных и лингвистических особенностей. В задачи исследования входило: проанализировать и описать условия семантической характеристики фразеологических компонентов, определить информативную емкость ФЕ, представленную в их содержательной структуре.

Ключевые слова: фразеологическая единица, семантика, компонент, устойчивость, метафоризация слова, слово в свободном сочетании.

шая - фразеологическим сочетаниям» [5, с. 123]. Некоторые ученые оставляют за рамками фразеологии такие единицы, в которых семантическая связь между значением фразеологического компонента и эквивалентным словом свободного употребления живо ощущается [8, с. 6; 12, с. 159]. В. Н. Телия, определяя объем фразеологии как все воспроизводимые обороты, составляющие, как и слова, инвентарь языка, отмечает: «... именно характер устойчивости есть искомое для фразеологии, так как воспроизводимость по традиции сама по себе не может считаться достаточным основанием для отнесения к языку, а не к речи каких-либо явлений» $[16$, с. 26$]$.

Другие исследователи стремятся определить сущность понятия устойчивости независимо от воспроизводимости. Так, Т.М. Фильченко считает, что «под устойчивостью понимается мера ограничения сочетаемости лексем» $[18$, с. 88], причем признаком ограниченности сочетаемости является предсказуемость. Но если ФЕ называть устойчивыми в таком смысле термина, то это никак не отличает их от свободных, также являющихся «устойчивыми». Отсюда недостаточность критерия устойчивости и стремление исследователей опереться на дополнительные признаки. «Критерий устойчивости при всей своей основательности не может быть признан абсолютным при определении состава объекта фразеологии. Он нуждается в проверке и поддержке со стороны других, не менее основательных критериев, в частности, «семантического» $[13$, с. 15]. 
Итак, граница явлений, охватываемых понятием фразеологии, то почти беспредельно расширяется, то сужается до очень ограниченного круга, в связи с этим существует немалое число определений фразеологизма, берущих за основу различные его конститутивные признаки. В соответствии с представлениями о границах фразеологии формируются представления о статусе фразеологического компонента, о его лексических и фразеологических характеристиках.

В аспекте соотношения формы и содержания ФЕ важно выделить те элементы фразеологического значения, которые могут быть соотнесены с отдельными лексическими компонентами или сочетаниями компонентов, определить свойства и функции этих компонентов.

Возможности расчленения фразеологического значения на части, соотносящиеся с отдельными лексическими компонентами, заложены в грамматической структуре ФЕ. Во фразеологической семантике могут сочетаться такие абстрактные элементы значения, как предметность и качественность, процессуальность и обстоятельственность. Они соотносятся прежде всего с теми лексическими компонентами, для которых являются категориальными, определяющими их принадлежность к тому или иному лексико-грамматическому классу слов. На эти абстрактные грамматические значения при соотнесении их с лексическими компонентами наслаиваются элементы фразеологического значения, содержащие конкретизированное обозначение и характеристику определенного предмета, действия, атрибутивного признака и т.д. Взаимодействие семантических элементов разной степени абстрактности, ассоциирующихся с одним и тем же лексическим компонентом, создает внутрифразовое значение данного компонента, обладающие иерархической организацией.

Например, в ФЕ дырявая память, дубовая голова, реветь белугой компоненты дырявая, дубовая, белугой не соотносятся семантически с соответствующими словами свободного употребления. Но благодаря своей грамматической оформленности и живым синтаксическим связям они соотносятся с определенными частями речи и выполняют функцию определителей при именах и глаголах. Эти компоненты ассоциируются с той частью фразеологического значения, которая связана с качественной характеристикой. В составе ФЕ они осмысляются как синонимы слов, с которыми при свободном употреблении в синонимические отношения не вступают. Так, компонент дубовая в ФЕ дубовая голова воспринимается как синоним слов тупая, бестолковая, компонент дырявая (дырявая память) как синоним прилагательного плохая. В таких образованиях явная семантическая автономность одного компонента обусловливает «остаточную» автономность другого компонента [9, с. 12]. В рассмотренных случаях семантическая структура ФЕ, их смыс- ловое членение обусловлены характером их построения, семантикой структурных типов словосочетаний, являющихся их генетической основой. Определяя семантику компонентов ФЕ, необходимо последовательно учитывать первичность общего значения устойчивого сочетания по отношению к смысловому содержанию составляющих его слов.

Направление семантического анализа ФЕ, как и других знаков языка, от общего значения к смысловому содержанию составляющих компонентов мотивируется механизмом языковой номинации, исходным моментом которого является семантическая интенция, или общий замысел высказывания [11, с.126], обусловливающий выбор формы, в которой получает выражение определенное языковое значение. Семантический анализ языковых структур всегда сопряжен с параллельным членением их формы: форма и значение, образующие неразрывное единство, «должны определяться друг через друга, и повсюду в языке их членение совместно» [3, с. 136].

Важнейшим этапом семантического анализа ФЕ яВляется определение ее значения и построение текста толкования - предложения или словосочетания, представляющего собой достаточное приближение к значению данной ФЕ. Далее должно следовать сопоставление структурной схемы ФЕ и ее семантического эквивалента. Обнаружение в этих структурах элементов изоморфизма свидетельствует о членимости фразеологического значения на части, соотносящиеся с отдельными лексическими компонентами или сочетаниями компонентов в составе ФЕ, и, следовательно, об определенной степени аналитизма значения данной ФЕ. Чем полнее изоморфизм сопоставляемых структур, тем более аналитическим является фразеологическое значение, тем менее оно абстрагировано от структурной схемы ФЕ, тем отчетливее членение ФЕ на компоненты знакового характера.

Приведем пример семантического анализа ФЕ выносить сор из избы. В «Фразеологическом словаре русского языка» под ред. А.И. Молоткова [19] ФЕ выносить сор из избы зафиксирована в двух значениях: 1) разглашать ссоры, дрязги между близкими людьми; 2) разглашать то, что касается узкого круга лиц и чего не должны знать другие. Сопоставляя структуру данных текстов толкования со структурной схемой рассматриваемой ФЕ, обнаруживаем определенную степень изоморфизма, выражающуюся в следующем: сравниваемые конструкции являются глагольно-субстантивными образованиями, включающими грамматически господствующий глагол и зависимое существительное в винительном падеже без предлога. В соответствии с данным структурно-грамматическим членением общая часть сформулированных значений «разглашать» ассоциируется прежде всего с глаголом выносить. 
Остальные лексические компоненты выражают в первом значении содержание «ссоры, дрязги между близкими людьми», во втором - «то, что касается узкого круга лиц и чего не должны знать другие». Это семантическое членение мотивировано лексико-грамматическим характером части слов, образующих ФЕ, и синтаксическими отношениями между ними.

Подобные семантические ассоциации лексических компонентов не нарушают смысловую целостность ФЕ, так как вычленяемые части их значения не распределяются непосредственно и полностью между отдельными компонентами. Любой смысловой оттенок, соотносящийся с каким-либо компонентом, принадлежит ФЕ в целом [4, с. 1160]. Семантика лексических компонентов опосредована значением и грамматической структурой ФЕ.

В результате семантических ассоциаций компонентов фразеологизмов со словами в составе синонимичных и изоморфных им по грамматической структуре сочетаний компоненты ФЕ могут заменяться соответствующими словами. В этом проявляется тенденция к эксплицированию элементов фразеологического значения. Например, в следующем употреблении ФЕ пить горькую чашу компонент пить заменен словом претерпевать (ср. со словосочетанием претерпевать тяжелые испытания, лишения, являющимся синонимом данной ФЕ): Ты можешь все употребить на красоту самого издания и таким образом доставить хлеб бедным художникам, которым приходится иногда претерпевать горькую чашу (Н. Гоголь. О «Современнике»). Можно отметить также следующие окказиональные употребления ФЕ, в которых слова, заменяющие компоненты ФЕ, эксплицируют определенные узуальные или окказиональные элементы фразеологического значения: говорить на ветер (Г. Данилевский. Княжна Тараканова) - ср.: бросать слова на ветер; падение с неба в жизнь (М. Булгаков. Белая гвардия) - ср.: падать с неба на землю; в мутной воде ловить свою презренную выгоду (А. Новиков. Впереди идущие) ср.: ловить рыбу в мутной воде.

Взаимодействие компонентов ФЕ со словами свободного употребления, выражающееся в их замене словами, значения которых в каком-либо плане сближаются со значениями этих компонентов, возможно лишь потому, что они интуитивно воспринимаются как слова с определенной смысловой структурой.

При рассмотрении семантических свойств компонентов ФЕ особый интерес представляет вопрос: может ли отдельный лексико-семантический вариант слова свободного употребления лечь в основу целой ФЕ, сохранив при этом свою семантическую наполненность?

Некоторые лингвисты отвечают на этот вопрос однозначно отрицательно. «Полная или частичная утрата компонентами «смысловых» свойств по преимуществу вызывается метафоризацией всего переменного словосочетания, а не каждого слова в отдельности, так что между метафоризацией свободного словосочетания и метафоризацией слова существует качественное различие. Если при метафоризации слова реализуется одно или несколько переносных значений, то при метафоризации свободного словосочетания слова деактуализируются (и вследствие этого в них не могут быть выделены дифференциальные признаки значения), как бы растворяются в общем смысле фразеологизма, не приобретая при этом переносного значения» [8, с. 70-71].

Существуют и иные точки зрения. Намечая три группы фразеологизмов по характеру их взаимосвязи с данными лексического уровня, В.Н. Телия указывает на фразеологические обороты, одним из компонентов которых является слово в свободном употреблении, а другим - констатирующее оборот слово в его специфической форме существования. «Исторически такие компоненты возникли, как правило, «отпочковавшись» от многозначного слова или сохранив след былого, сейчас уже умершего употребления слова» [16, с. 46].

Последняя точка зрения нам кажется более убедительной, так как существует большое количество ФЕ, смыслообразующим компонентом которых может являться лексико-семантический вариант слова свободного употребления. Для подтверждения этой мысли целесообразно вернуться к проблеме различных типов устойчивости. Ш. Балли выделил два типа устойчивости фразеологизмов: фразеологические группы, устойчивость которых имеет узуально-стилистический характер, и фразеологические единства, устойчивость которых обусловлена тем, что «связи между элементами фразеологического оборота не осознаются говорящими точно так же, как и значения самих элементов - образно выражаясь, механизм заржавел» [2, с. 101].

Иллюстрируя положение о наличии двух типов устойчивости, В.М. Огольцев приводит в качестве примера такие ФЕ: скоропостижно умереть, пить чай вприкуску, плакать навзрыд - с одной стороны, и махнуть рукой, обвести вокруг пальча - с другой. И те и другие формируют, по мнению автора, устойчивые сочетания. Но устойчивость первых не имеет ничего общего с семантической неразложимостью вторых. А устойчивость вторых не содержит в себе какой-либо особой (в отличие от «свободных» словосочетаний) сочетаемости лексем. Первый тип автор называет «относительной устойчивостью», которая характеризуется определенной степенью сочетаемости лексем, т. е. ограниченной лексической валентностью. Второй тип устойчивости выступает как «безотносительная устойчивость» [10, с. 54-55]. Эта устойчивость во3никает в результате метафорического переосмысления словосочетания, семантического сдвига. 
Не менее важным является фактор, влияющий на характер устойчивости, - это различные типы лингвистической абстракции. Так, принципиально отличаются друг от друга ФЕ, образованные в результате целостного переосмысления всего словосочетания, а не всех его компонентов, т. е. при образном назывании определенного отрезка действительности словосочетанием, уже называющем другой отрезок действительности. Это называется совмещенным видением двух картин (сесть в лужу, гонять собак) и ФЕ, которые имеют в своем составе один или несколько семантически преобразованных компонентов (черные мысли, белый день).

Следует отметить, что речь идет вовсе не о полной или частичной десемантизации, ибо при таком подходе обе группы как бы ставятся в один ряд, - здесь речь идет о принципиально различных приемах метафоризации, качественно различных типах формирования фразеологического значения. Первое основано на метафорическом переосмыслении словосочетания, второе - на метафоризации одного или нескольких компонентов и их взаимодействии. Именно применительно к первой группе нельзя говорить о сумме значения компонентов, а применительно ко второй - это возможно.

По этому поводу И.И. Савогина пишет: «Целостное значение фразеологизма есть результат целостной семантической трансформации словесного комплекса-прототипа, а не следствие его последовательного покомпонентного переосмысления» [14, с. 160]. Следовательно, фразеологизм как неделимое устойчивое сочетание слов противопоставляется семантически делимым и обладающим различной степенью семантической устойчивости на лексическом и грамматическом уровне фразеологическим сочетаниям. Именно на примере второй группы можно доказать, что смыслообразующий компонент ФЕ имеет тесную связь со словом свободного употребления, так как этот компонент связывается лишь с одним из значений этого слова, с одним из его лексикосемантических вариантов, чем собственно и объясняется его ограниченная сочетаемость, т. е. компонент - это не слово во всей его семантической полноте, это лишь его лексико-семантический вариант, абстрагированный от остального семантического наполнения, присущего этому слову.

Продемонстрируем это примерами из художественных текстов.

Перед отъездом из Петрограда он получил наказ провести в европейской печати ряд статей, чтобы, сколько возможно, парализовать желтую прессу (А. Толстой. Эмигранты).

Нельзя сразу долбить читателя по башке вашими передовицами. Я его заинтересую. Что вы скажете о серии очерков - «С фонарем по Парижу?». Пусть это будет немного желто - все же лучше, чем ваши осиновые колья (А. Толстой. Эмигранты).

Да... Помешали кое-какие внешние причины, например, присутствие в Булони американской армии в миллион штыков... Но главное - это желтая сволочь... желтая сволочь!.. (А. Толстой. Эмигранты).

Теперь я верю, это просто промах реакции, - заметка желтая и помешена Митькой Рубинштейном. Вы знаете, что он играет на понижении курса? (А. Толстой. Эмигранты).

ФЕ желтая пресса зафиксирована в «Толковом словаре русского языка» под редакцией Д.Н. Ушакова [17] и имеет следующее пояснение - «беспринципный, бульварно-сенсационный». В этом словаре ФЕ желтая пресса приводится в качестве примера, иллюстрирующего переносное значение слова желтый - соглашательский, реформистский, продажный, предательский.

В «Словаре современного русского литературного языка» [15] слово желтый имеет среди прочих и такое толкование - перен. продажный, предательский, изменчивый.

Соответственно веяниям времени семантическое наполнение слова желтый в переносном значении несколько колебалось. Но суть оставалась прежней. Сема «беспринципный» реализуется как в раннем, так и более позднем толковании этого слова. Эта же сема реализуется в составе ФЕ желтая пресса.

В приведенных примерах существует практически полная семантическая адекватность лексико-семантического варианта слова желтый как в составе ФЕ, так и в свободных словосочетаниях. В каждом примере можно выделить некоторые дополнительные семы: так, в первом случае - это скорее, предательский, буржуазный (речь идет об эмигрантской прессе, рекламирующей ложные ура-патриотические настроения); во втором беспринципный, бульварно-сенсационный; в третьем - соглашательский, продажный, предательский; и четвертом - беспринципный. Но это дополнительные семы, неизбежно возникающие в рамках определенного контекста, не меняют основного смысла анализируемого нами лексико-семантического варианта слова желтый.

Различие между лексико-семантическим вариантом слова в свободном употреблении и этим же лексикосемантическим вариантом в составе ФЕ заключается в том, что «фразеологически связанный лексико-семантический вариант воспринимается как нечто более самостоятельное, автономное, чем это же значение, реализованное в свободном контексте» [6, с. 173]. Иначе говоря, 
переносное, образное значение слова в составе свободного сочетания накладывается на прямое и на возможные другие переносные значения этого же слова и воспринимается на их фоне, а компонент ФЕ иных значений не имеет и иметь не может.

Поэтому в художественном тексте можно встретить несколько ФЕ, включающих разные лексико-семантические варианты одного и того же слова, в одном синтаксическом целом, или даже в одном предложении.

1. К вечеру Красная армия ворвалась в Царское село, - дрались под столетними липами, у Фридендальских и Орловских ворот. Белые покатились на юг, цепляясь за Красное село, за Гатчину, за Лугу (А. Толстой. Простая душа).

В первом случае компонент красная имеет значение - революционная (и только!), а во втором - красное красивое (и только!), потому что в составе ФЕ лексико-семантический вариант утрачивает свой «семантический» фон за счет фразеологической связанности.

2. Дожили, батенька мой, до красного денечка! - на другой день побежала Катя на Красную площадь глядеть, как пушки возят, как сдаются в Кремле запасные солдаты, как по Никольской ведут приставов без шапок, с порванными погонами, как вешают Красный флаг на Минина... (А. Толстой. Простая душа).

И здесь в первом случае - красного - счастливого, радостного; во втором - красную - красивую; в третьем красный - революционный.

Аналогичного явления в употреблении лексико-семантических вариантов одного слова в составе свободных словосочетаний в художественных текстах не встречается.

Однако существует ФЕ, в составе которых реализуется такое значение слова, которое в свободных словосочетаниях не встречается. Например, ФЕ желтый дом, зафиксированная в отмеченных выше словарях, а также в «Толковом словаре живого великорусского языка» В.И. Даля [7] и во «Фразеологическом словаре русского языка» под редакцией А.Н. Молоткова [19] имеет везде одинаковое толкование, - дом для умалишенных, психиатрическая больница. В современных словарях имеет помету - устар., в более старых - помету разг. больница для умалишенных.

Тот факт, что значение психически больной, ненормальный, сумасшедший - реализуется у слова желтый только в составе ФЕ желтый дом, объясняется причинами исторически-бытовыми. Согласно данным словарей значение это не вышло за пределы ФЕ в виде лексикосемантического варианта слова желтый, следовательно, значение такого типа является фразеологически обусловленным, так как оно уже не связано с системой значений омонимичного свободного эквивалента. Но примечателен факт употребления этого лексико-семантического варианта слова желтый в составе сочетания желтая школа, т. е. вспомогательная школа для умственно отсталых, психически неполноценных детей:

- А почему, собственно, пришли ко мне? Разве одни мои дети находятся в желтой школе?

- Почему желтая?

- Так ее называют в нашем городе (А. Толстой. Эмигранты).

Действительно, почему желтая? Наверное, потому что новое устойчивое сочетание образовалось по аналогии с уже существующей ФЕ желтый дом. Но две ФЕ желтый дом и желтая школа различаются только тем, что первая означает больницу определенного профиля, а вторая - учебное заведение аналогичной специализации. Тот факт, что один компонент ФЕ попал в другую ФЕ для выражения аналогичного понятия, свидетельствует об известной семантической самостоятельности этого компонента, о том, что он сохранил в составе ФЕ некую смысловую автономию. Освещение тех или иных семантических свойств компонентов ФЕ и элементов фразеологического значения открывает путь к установлению типов и свойств семантических отношений в рамках структуры фразеологического значения.

Основное свойство анализа ФЕ заключается в необходимости учета лексической и грамматической систем, а также особенностей их проявления. Фразеологически связанный лексико-семантический вариант слова воспринимается как нечто более самостоятельное, чем этот же лексико-семантический вариант слова, реализованный в свободном сочетании. Образное значение слова в составе свободного сочетания основывается на взаимодействии прямого и переносного значений этого же слова и воспринимается на их фоне.

Важным фактором, влияющим на характер устойчивости, являются различные типы лингвистической абстракции. Фразеологизм часто образуется вследствие метафорического переосмысления свободных словосочетаний такого же лексического состава. Семантическая связь между значением фразеологического компонента и эквивалентным словом в свободном сочетании четко ощущается.

При функционировании ФЕ в речи фразеологическое значение видоизменяется прежде всего в денотативном плане. При этом в зависимости от характера предметов и явлений, обозначаемых ФЕ в контексте, часто преобразуются лишь отдельные элементы фразеологического значения, те, которые способны передать специфику единичных явлений и ситуаций. Функция обозначения элементов определенной ситуации, выполняемая ФЕ и 
их отдельными компонентами, создает условия для эксплицирования актуализируемых в данной ситуации элементов фразеологического значения.

Степень и характер изоморфизма грамматической и смысловой структуры ФЕ неразрывно связаны с особенностями фразеологической абстракции. Значение
ФЕ абстрагируется от семантических категорий, которые присущи словам и сочетаниям слов, являющимся ее генетической основой. Одно и то же слово в составе разных ФЕ не может полностью сохранять смысловое тождество, так как в каждом случае с ним ассоциируется часть определенного фразеологического значения, несущая на себе отпечаток целого.

\section{ЛИТЕРАТУРА}

1. Архангельский В.Л. Устойчивые фразы в современной русском языке. Основы теории устойчивых фраз и проблемы общей фразеологии. Ростов-наДону: РГУ, 1964, 315 с.

2. Балли Ш. Французская стилистика. М.: Изд-во иностр. лит-ры, 1961, 394 с.

3. Бенвенист Э. Общая лингвистика. М.: Прогресс, 1974, с. 136.

4. Ван, Синьцзюй. Фразеологизмы, характеризующие поведение человека, в русском и китайском языках // Вестник Башкирского университета. 2017. T. 22. №4. с. 1159-1164.

5. Виноградов В.В. Основные понятия русской фразеологии как лингвистической дисциплины // Виноградов В.В. Избранные труды. Лексикология и лексикография. М.: Наука, 1977, с. 118-139.

6. Гамидов И.Г. Философия грамматики паремио-фразеоллогических единиц. Баку: Мутарджим, 2017, 368 с.

7. Даль. В.И. Толковый словарь живого великорусского языка. М.: Русский язык, 1989, Т. І. 699 с.

8. Жуков В.П. Семантика фразеологических оборотов. М.: Просвещение, 1978, 160 с.

9. Максимец С.В. Ценности лингвокультурного сообщества в зеркале фразеологии. Автореф. дис. ... канд. филол. наук. Ростов-на-Дону, 2015, 23 с.

10. Огольцев В.М. Устойчивые сравнения в системе русской фразеологии. Л.: ЛГУ, 1978, 159 с.

11. Одинцова, И.В. Фреймовое моделирование семантической концептосферы, отраженной во фразеологизмах // Полипарадигмальные контексты фразеологии XXI века: Матер. междун. научн. конф. Тула: ТППО, 2018, с. 124-128.

12. Ордин И.Ю. К вопросу о специфике образной основы эквивалентных фразеологизмов // Вавилонская башня - 2. Слово. Текст. Культура. Чтения 20022009. М., 2009, с. 154-162.

13. Постнова А.И. Роль контекста при определении значения и границ фразеологизма // Известия Сибирского отделения АН СсСР. Серия истории филологии и философии, 1990. Вып. 3, с. 13-18.

14. Савогина. И.И. Функционирование трансформированных фразеологических единиц в массово-информационном дискурсе (на примере интернет-прес(ы) // Полипарадигмальные контексты фразеологии XXI века: Материалы междун. научн. конф. Тула: ТППО, 2018, с. 159-163.

15. Словарь современного русского литературного языка. М-Л., 1948-1965.

16. Телия В.Н. Что такое фразеология? М.: Наука, 1966, 86 с.

17. Толковый словарь русского языка: В 4 т. / Под ред. Д.Н. Ушакова. М.: «Сов. энцикл.», 1935-1940.

18. Фильченко Т.М. Фразеологический образ в языковой модели пространства // Филологические науки, 2006, № 2, с. 87-94.

19. Фразеологический словарь русского языка / Под. ред. А.Н. Молоткова. М.: «Сов. энцик», 1968, 543 с.

(с) Алиева Усния Новруз гызы (al_hus@list.ru). 